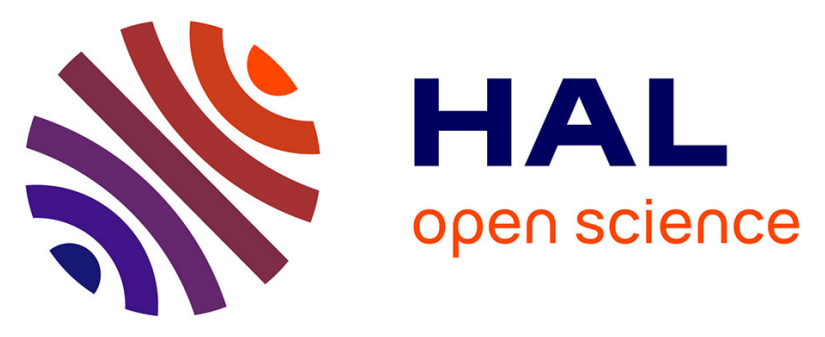

\title{
Experimental and Numerical Analysis of Recovery Stress In NI47TI44NB9 Shape Memory Alloys: Application to Tightening
}

Boris Piotrowski, Etienne Patoor, Tarak Ben Zineb, Andre Eberhardt

\section{- To cite this version:}

Boris Piotrowski, Etienne Patoor, Tarak Ben Zineb, Andre Eberhardt. Experimental and Numerical Analysis of Recovery Stress In NI47TI44NB9 Shape Memory Alloys: Application to Tightening. 3rd Annual Meeting of the ASME/AIAA Smart Materials, Adaptive Structures, and Intelligent Systems (SMASIS)/Symposium on Modeling, Simulation and Control, Sep 2010, Philadelphie, PA, United States. pp.97-103, 10.1115/SMASIS2010-3693 . hal-01769343

\section{HAL Id: hal-01769343 \\ https://hal.science/hal-01769343}

Submitted on 5 Jan 2020

HAL is a multi-disciplinary open access archive for the deposit and dissemination of scientific research documents, whether they are published or not. The documents may come from teaching and research institutions in France or abroad, or from public or private research centers.
L'archive ouverte pluridisciplinaire HAL, est destinée au dépôt et à la diffusion de documents scientifiques de niveau recherche, publiés ou non, émanant des établissements d'enseignement et de recherche français ou étrangers, des laboratoires publics ou privés.

\section{(c)(1)}

Distributed under a Creative Commons Attribution| 4.0 International License 


\section{EXPERIMENTAL AND NUMERICAL ANALYSIS OF RECOVERY STRESS IN $\mathrm{NI}_{47} \mathrm{TI}_{44} \mathrm{NB}_{9}$ SHAPE MEMORY ALLOYS: APPLICATION TO TIGHTENING}

\section{Boris Piotrowski * Etienne Patoor}

\author{
Arts et Metiers Paristech, LPMM \\ 4, rue Augustin Fresnel 57070 \\ METZ France
}

\author{
Tarak Ben-Zineb \\ NancyUniversity, CNRS, LEMTA \\ Vandoeuvre-les-Nancy, France
}

\author{
Andre Eberhardt \\ ENIM, LPMM \\ Paul Verlaine University \\ Metz, France
}

\begin{abstract}
$\mathrm{Ni}_{47} \mathrm{Ti}_{44} \mathrm{Nb}_{9}$ Shape Memory Alloys (SMAs) are widely considered for tightening applications. The alloy is composed of a NiTi SMA matrix containing niobium precipitates. A specific thermomechanical treatment strongly increases the transformation hysteresis in these alloys, what improves the tightening effciency.

Tightening pressures exhibited by $\mathrm{Ni}_{47} \mathrm{Ti}_{44} \mathrm{Nb}_{9}$ rings are experimentally investigated. Strain gage measurements allow to monitor the tightening pressure using a home test bed. Evolutions with temperature are recorded.

A thermo-mechanical constitutive law, specific for $\mathrm{Ni}_{47} \mathrm{Ti}_{44} \mathrm{Nb}_{9}$, is proposed. It is based on the Mori-Tanaka scale transition technique by considering the precipitates as elastic-plastic inclusions embedded in the SMA matrix. The resulting effective law is implemented, and validated in ABAQUS via UMAT subroutine. Experimental tests are simulated by Finite Element Modeling, and comparisons are performed.
\end{abstract}

\section{INTRODUCTION}

Commercial $\mathrm{Ni}_{47} \mathrm{Ti}_{44} \mathrm{Nb}_{9}$ Shape Memory Alloy is generally adopted for industrial connection applications, thanks to its wide transformation hysteresis. It has been shown that a specific mechanical treatment stabilizes the martensite phase [1-3]. Re-

*Email: boris.piotrowski@esstin.uhp-nancy.fr verse transformation temperature $A_{s}$ increases from $-18{ }^{\circ} \mathrm{C}$ to $80{ }^{\circ} \mathrm{C}$ [4] which leads to a hysteresis width larger than $160{ }^{\circ} \mathrm{C}$. In comparison with classical NiTi for which hysteresis width is lower than $40{ }^{\circ} \mathrm{C}$, this strongly increases the application field of this alloy.

$\mathrm{Ni}_{47} \mathrm{Ti}_{44} \mathrm{Nb}_{9}$ microstructure is complex, composed of various phases: NiTi polycristal, rich-niobium precipitates and richtitanium precipitates [5]. A thermo-mechanical model taking into account this microstructure has been proposed $[6,7]$. It considers niobium precipitates as elastic-plastic inclusion embedded in a NiTi matrix. Chemisky-Duval model describes NiTi shape memory alloy constitutive law [8]. The elastic-plastic constitutive law for inclusions is a classical one proposed by Wilkins, through Simo and Hughes radial return algorithm $[9,10]$. MoriTanaka scale transition technique [11] leads to the effective behavior. Parameter identification and model validation are performed using an experimental dataset. This validation is proposed elsewhere [6].

In this study, the $\mathrm{Ni}_{47} \mathrm{Ti}_{44} \mathrm{Nb}_{9}$ rings tightening is investigated. The aim is to compare experimental and numerical results in order to test the model's ability to accurately predict the $\mathrm{Ni}_{47} \mathrm{Ti}_{44} \mathrm{Nb}_{9}$ behavior. $\mathrm{Ni}_{47} \mathrm{Ti}_{44} \mathrm{Nb}_{9}$ rings are opened from martensitic state, placed around Inconel 718 elastic pipes instrumented by strain gages. Heating induces reverse transformation and tightening of rings on pipes. The contact pressure evolution with temperature is recorded and compared with numerical re- 


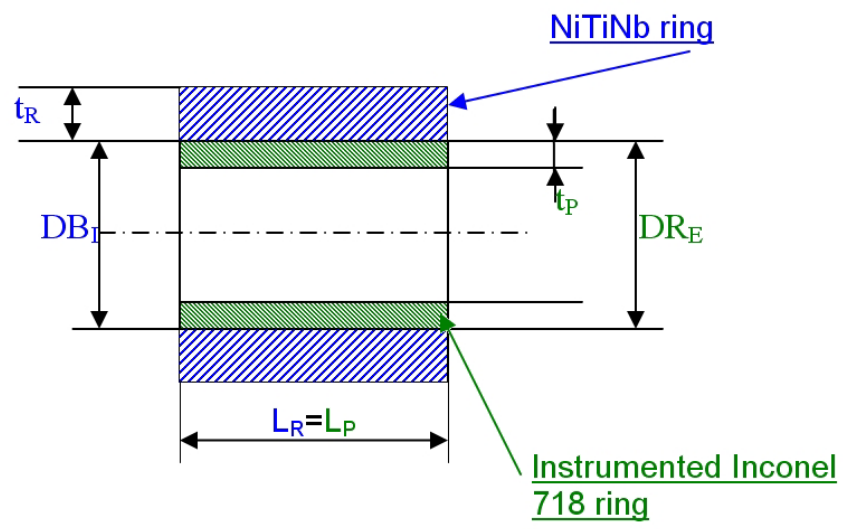

FIGURE 1. DEVICE ANALYZED BY EXPERIMENTAL AND NUMERICAL WAY $\mathrm{Ni}_{47} \mathrm{Ti}_{44} \mathrm{Nb}_{9}$ RING TIGHTENING ON INCONEL ELASTIC RING [6]

sults. Two different thickness rings are considered.

Experimental investigations and results are firstly presented, followed by numerical part which describes the $\mathrm{Ni}_{47} \mathrm{Ti}_{44} \mathrm{Nb}_{9}$ model and finite element model. Experimental and numerical results are then compared and discussed in order to validate the adopted $\mathrm{Ni}_{47} \mathrm{Ti}_{44} \mathrm{Nb}_{9}$ model and highlight the model limitations.

\section{EXPERIMENTAL ANALYSIS}

The experimental device developed to monitor the tightening pressure provided by a SMA ring is presented in Fig. 1. It is composed by a $\mathrm{Ni}_{47} \mathrm{Ti}_{44} \mathrm{Nb}_{9}$ ring and an Inconel 718 ring. The internal diameter of the first one is $D R_{I}$, thickness is $t_{R}$ and length $L_{R}$. The Inconel 718 external diameter is $D P_{E}$, thickness is $t_{P}$ and length $L_{P}$. The thermoelastic material parameters of Inconel 718 are a Young modulus of $205 \mathrm{GPa}$, a Poisson ratio coefficient of 0.29 and a thermal expansion coefficient of $13 \mu \mathrm{m} /\left(\mathrm{m}^{\circ} \mathrm{C}\right)$. The plastic yield stress is about $1000 \mathrm{MPa}$.

Two $\mathrm{Ni}_{47} \mathrm{Ti}_{44} \mathrm{Nb}_{9}$ rings are supplied by Intrinsic Devices in an "opened state", and internal diameters before opening is unknown. The two configurations, called "thin", and "thick", are summarized in Tab. 1. Rings are chosen so that internal diameter after opening is equal in both configurations, but with various thicknesses. "thin" and "thick" rings are supplied with different length. The ratio $t_{R} / L_{R}$ is of 0.058 in thin configuration, and 0.352 in thick one. Elastic ring length is chosen in order to have same than the $\mathrm{Ni}_{47} \mathrm{Ti}_{44} \mathrm{Nb}_{9}$ one, to avoid edge effects.

\section{Tightening pressure measurement and cycle}

The internal face of elastic ring is instrumented by three strain gages positioned in a rosette-like layout. The $45^{\circ}$ strain rosette permits to determine the three independent components
TABLE 1. RING DIMENSION IN THE TWO CONFIGURATIONS

\begin{tabular}{cccccc}
\hline $\mathrm{N}^{\circ}$ & $\begin{array}{c}\text { Reference } \\
\text { NiTiNb ring }\end{array}$ & \multicolumn{2}{c}{$D R_{I}(\mathrm{~mm})$} & $t_{R}$ & $L_{R}$ \\
& opened & heated & $(\mathrm{mm})$ & \\
\hline 1-thin Tn & AHM2565-0089-1526 & 25.65 & 24.59 & 0.89 & 15.26 \\
2-thick Tck & AHM2565-0358-1016 & 25.65 & 24.47 & 3.58 & 10.16 \\
\hline $\mathrm{N}^{\circ}$ & $t_{R} / L_{R}$ & $D P_{E}$ & $t_{P}$ & $L_{P}$ & \\
& $(\mathrm{~mm})$ & $(\mathrm{mm})$ & $(\mathrm{mm})$ & $(\mathrm{mm})$ & \\
\hline 1-thin & 0.058 & 25.50 & 1.75 & 15.55 & \\
2-thick & 0.352 & 25.50 & 1.75 & 10.40 & \\
\hline
\end{tabular}

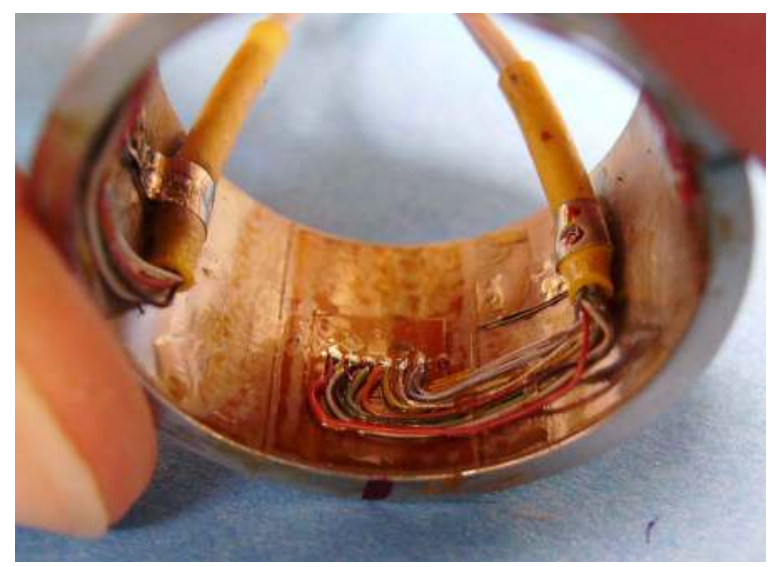

FIGURE 2. STRAIN MEASUREMENT ON INTERNAL ELASTIC RING WITH $45{ }^{\circ}$ STRAIN ROSETTE

of plane strain, as shown in Fig. 2. An analytical relationship is used to calculate the tightening pressure induced by $\mathrm{Ni}_{47} \mathrm{Ti}_{44} \mathrm{Nb}_{9}$ ring on elastic one. The tightening pressure $\mathrm{P}$ generated on external face of an elastic ring (Young modulus $\mathrm{E}$, internal radius $R_{i}$ and external radius $R_{e}$ ) depends on internal face axial $\left(\varepsilon_{z}\right)$ and tangential $\left(\varepsilon_{\theta}\right)$ strains, by the Eqn. 1 [6].

$$
P=-\frac{E}{2(1+v)} \frac{R_{e}^{2}-R_{i}^{2}}{R_{e}^{2}}\left(\varepsilon_{\theta}-\varepsilon_{z}\right)
$$

Each test is performed twice for each configuration, the first time with a heating rate of $2{ }^{\circ} \mathrm{C} / \mathrm{min}$ and a second with a heating rate of $10{ }^{\circ} \mathrm{C} / \mathrm{min} . \mathrm{Ni}_{47} \mathrm{Ti}_{44} \mathrm{Nb}_{9}$ and elastic rings are assembled into a climatic chamber. Heating is applied up to $175^{\circ} \mathrm{C}$, followed by cooling to $-30{ }^{\circ} \mathrm{C}$ after a stabilization period of 15 minutes. Disassembly is achieved using liquid nitrogen. 

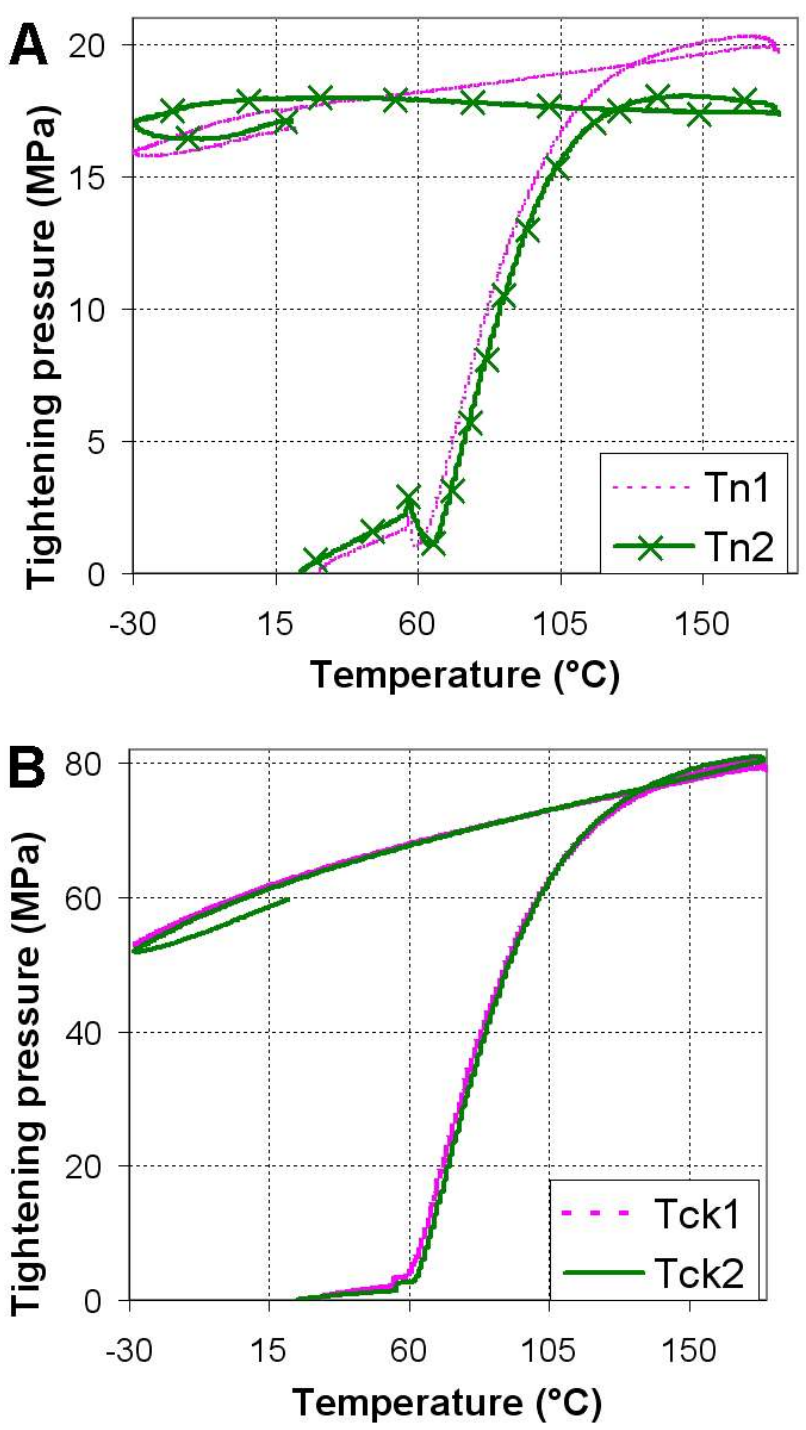

FIGURE 3. CONTACT PRESSURE EVOLUTION WITH TEMPERATURE OF THIN (A) AND THICK (B) $\mathrm{Ni}_{47} \mathrm{Ti}_{44} \mathrm{Nb}_{9}$ RINGS ON INCONEL 718 ELASTIC RINGS INSTRUMENTED WITH STRAIN GAGES [6]

\section{Experimental results}

Figure 3 shows the contact pressure evolution with temperature in the two configurations. Tn1 and Tck1 are tests conducted respectively with temperature rate of $2{ }^{\circ} \mathrm{C} / \mathrm{min}$ in thin and thick configurations, $\mathrm{Tn} 2$ and Tck 2 are those conducted with $10^{\circ} \mathrm{C} / \mathrm{min}$. One can see that temperature rate has no influence on results in thick configuration, whereas there are some differences in thin one. Three phases are observed:

Between 30 and $60{ }^{\circ} \mathrm{C}$, a slight increase in clamping pressure of $0.04 \mathrm{MPa} /{ }^{\circ} \mathrm{C}$ is observed.

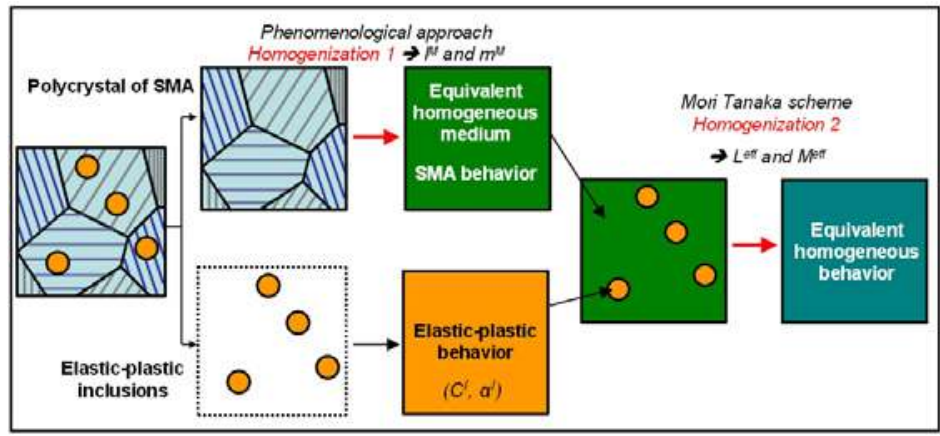

FIGURE 4. HOMOGENIZATION STRATEGY LEADING FROM SMA POLYCRYSTALLINE MATRIX WITH SPHERICAL ELASTIC-PLASTIC INCLUSION TO EQUIVALENT HOMOGENEOUS MEDIUM [6]

Between 65 and $175{ }^{\circ} \mathrm{C}$, an increase of $0.27 \mathrm{MPa} /{ }^{\circ} \mathrm{C}$ is observed in the thin configuration until $120{ }^{\circ} \mathrm{C}$, followed by saturation. In thick configuration, the increase is of 1.6 $\mathrm{MPa} /{ }^{\circ} \mathrm{C}$ until $100{ }^{\circ} \mathrm{C}$, followed by a progressive saturation. On cooling, between 175 and $-28^{\circ} \mathrm{C}$, a very low tightening pressure evolution decreasing is observed in thin configuration $\left(0.015 \mathrm{MPa} /{ }^{\circ} \mathrm{C}\right)$, and $0.12 \mathrm{MPa} /{ }^{\circ} \mathrm{C}$ in thick one.

The first and third phase are due to the difference between rings thermal expansion: Inconel 718 thermal expansion coefficient is higher than $\mathrm{Ni}_{47} \mathrm{Ti}_{44} \mathrm{Nb}_{9}$ one. The second phase corresponds to the reverse transformation. The loss of tightening force between the first two phases in thin configuration corresponds to the reorientation of a part of martensite.

\section{NUMERICAL ANALYSIS $\mathrm{Ni}_{47} \mathrm{Ti}_{44} \mathbf{N b}_{9}$ model}

Experimental investigations of $\mathrm{Ni}_{47} \mathrm{Ti}_{44} \mathrm{Nb}_{9}$ show $\mathrm{Nb}$-rich precipitates embedded into a matrix phase mainly composed of NiTi. They have also show that Nb-rich precipitates have elasticplastic behavior. They are considered as homogeneity distributed inclusions into a NiTi matrix, with a low volume fraction (10 \%) [5].

Considering this microstructure, the Mori-Tanaka transition scale scheme is adopted to derive the effective thermomechanical constitutive law, as illustrated in Fig. 4 ( $M$ and $I$ respectively denote Matrix and Inclusion). The RVE is composed of SMA Matrix (NiTi) with niobium inclusions. Inclusions are modeled with a spherical shape by an elastic-plastic model $[9,10]$ which leads to the following elastic-plastic constitutive equation:

$$
\dot{\sigma}_{i j}^{I}(r)=l_{i j k l}^{I}(r) \dot{\varepsilon}_{k l}^{I}(r)-c_{i j k l}^{I}(r) \alpha_{k l}^{I} \dot{T}
$$


$l^{I}$ and $\alpha^{I}$ are respectively the mechanical and thermal tangent operators, and $c^{I}$ the fort order elastic tensor.

NiTi matrix behavior is described with a macroscopic model [12]. This model takes into account the main SMA physical phenomena and its material parameters are easy to identify. The SMA matrix constitutive law is derived in an incremental way (Eqn. 3):

$$
\dot{\sigma}_{i j}^{M}(r)=l_{i j k l}^{M}(r) \dot{\varepsilon}_{k l}^{M}(r)-m_{i j}^{M} \dot{T}
$$

$l^{M}$ and $m^{M}$ are respectively the mechanical and thermal tangent operators.

The effective constitutive law is obtained by solving an implicit problem. The strain inside each phase is defined as follow (Eqn. 4 and 5):

$$
\begin{gathered}
\dot{\varepsilon}_{m n}^{I}=A_{m n i j}^{M T} \dot{E}_{i j} \\
\dot{\varepsilon}_{m n}^{M}=\frac{1}{1-z}\left(\left(I_{m n i j}-z A_{m n i j}^{M T}\right) \dot{E}_{i j}\right)
\end{gathered}
$$

with the Mori-Tanaka transition scale tensor (Eqn. 6):

$$
A_{m n i j}^{M T}=\left[I_{i j m n}-(1-z) T_{i j k l}^{I I}\left(l_{k l m n}^{M}-l_{k l m n}^{I}\right)\right]^{-1}
$$

Strain in inclusion and in matrix can derived from macroscopic strain $(4,5)$. Consequently, by taking into account the constitutive equations for matrix (3) and inclusion (2), the effective constitutive law is derived as follow:

$$
\dot{\Sigma}_{i j}=z \dot{\sigma}_{i j}^{I}+(1-z) \dot{\sigma}_{i j}^{M}=L_{i j m n}^{e f f} \dot{E}_{m n}-M_{i j}^{e f f} \dot{T}
$$

with the mechanical et thermal effective tangent operators (Eqn. $8,9)$ :

$$
\begin{gathered}
L_{i j m n}^{e f f}=z\left(l_{i j k l}^{I}-l_{i j k l}^{M}\right) A_{k l m n}^{M T}+l_{i j m n}^{M} \\
M_{i j}^{e f f}=m_{i j}^{M}+z\left(c_{i j k l}^{I} \alpha_{k l}^{I}-m_{i j}^{M}\right)
\end{gathered}
$$

Material parameters have been identified thanks to experimental tests [6, 13-16]. Table 2 presents adopted parameters for $\mathrm{Ni}_{47} \mathrm{Ti}_{44} \mathrm{Nb}_{9}$ simulation. $E^{M}, v^{M}, \alpha^{M}$ and $E^{I}, v^{I}, \alpha^{I}$ represent
TABLE 2. MATERIAL PARAMETER FOR PREDEFORMED $\mathrm{Ni}_{47} \mathrm{Ti}_{44} \mathrm{Nb}_{9}$ SIMULATION

\begin{tabular}{ccccc}
\hline$E^{M}$ & $v^{M}$ & $\alpha^{M}$ & $\varepsilon_{\text {trac }}^{T}$ & $\varepsilon_{\text {comp }}^{T}$ \\
$80 \mathrm{GPa}$ & 0.3 & $8 \mu \mathrm{m} /\left(\mathrm{m}^{\circ} \mathrm{C}\right)$ & 0.02 & 0.016 \\
\hline$b$ & $M_{s}$ & $A_{f}$ & $r_{f}$ & $F_{\bar{\varepsilon}^{T}}^{\max }$ \\
$10 \mathrm{MPa} /{ }^{\circ} \mathrm{C}$ & $-101{ }^{\circ} \mathrm{C}$ & $63^{\circ} \mathrm{C}$ & 0.7 & $125 \mathrm{MPa}$ \\
\hline$H_{f}$ & $H_{\varepsilon}$ & $H_{\text {twin }}$ & $E^{I}$ & $v^{I}$ \\
$5 \mathrm{MPa}$ & $2100 \mathrm{MPa}$ & $40 \mathrm{GPa}$ & $53 \mathrm{GPa}$ & 0.3 \\
\hline$\alpha^{I}$ & $\sigma^{Y}$ & $H^{i s o}$ & $n$ & $z$ \\
$8 \mu \mathrm{m} /\left(\mathrm{m}{ }^{\circ} \mathrm{C}\right)$ & $70 \mathrm{MPa}$ & $450 \mathrm{MPa}$ & 4 & 0.1
\end{tabular}

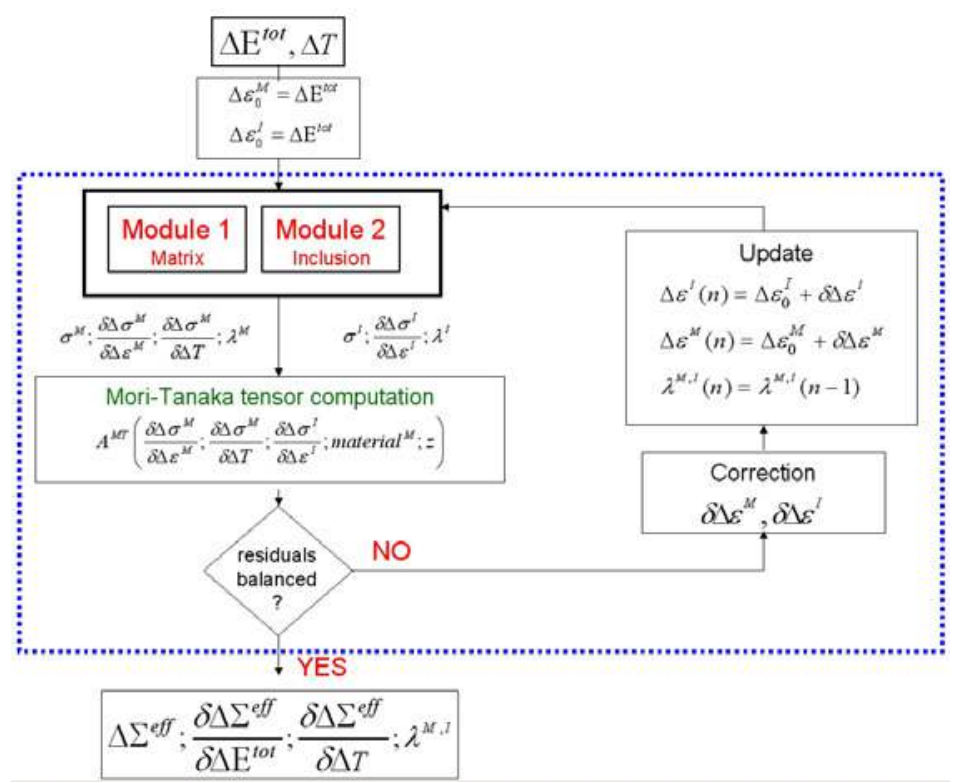

FIGURE 5. ADOPTED IMPLICIT RESOLUTION SCHEME TO DETERMINE EFFECTIVE TANGENT OPERATORS [6]

respectively thermoelastic behavior in matrix and inclusion (Young modulus, Poisson ratio, thermal expansion). The matrix phase transformation parameters are the maximal transformation strain in tension $\left(\varepsilon_{\text {trac }}^{T}\right)$ and compression $\left(\varepsilon_{\text {comp }}^{T}\right)$, the transformation temperatures $\left(M_{s}\right.$ and $\left.A_{f}\right)$, their variation with stress $(b)$, an internal loop parameter $\left(r_{f}\right)$, the critical reorientation stress $\left(F_{\bar{\varepsilon}^{T}}^{\max }\right)$ and three interaction parameters $\left(H_{f}, H_{\varepsilon}\right.$ and $\left.H_{t w i n}\right)$. The plastic inclusion parameters are the elastic Yield stress $\left(\sigma^{Y}\right)$ and two hardening parameters $\left(H^{i s o}\right.$ and $\left.n\right)$. $z$ parameter represents the inclusion volume fraction.

The resolution of the implicit system is described in Fig. 5. In the first iteration, strain inside matrix and inclusion is assumed equal to effective strain. Matrix and inclusion systems are unbalanced with this strain. Stress, tangent operators and internal 


\section{Inconel 718 rings}

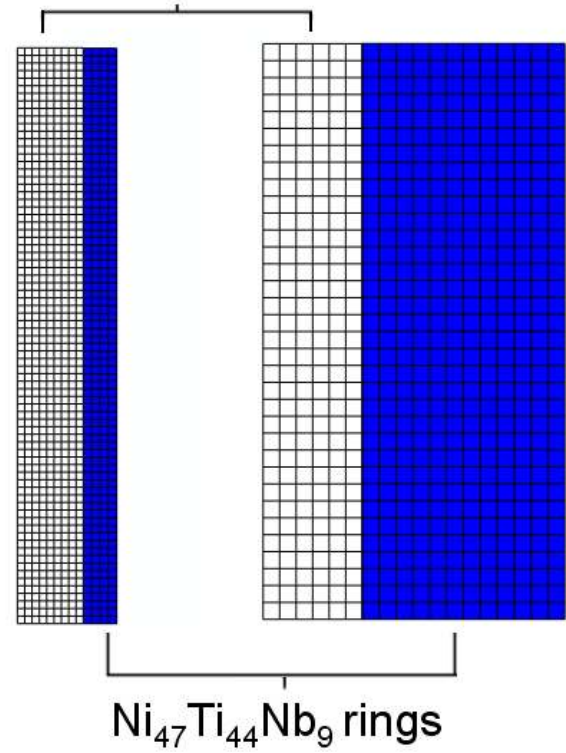

FIGURE 6. AXISYMMETRIC MODELISATION OF THE TWO STUDIED DEVICES - MESH OF THIN (LEFT) AND THICK (RIGHT) CONFIGURATIONS

variables $(\Lambda)$ of each phase are then computed. Mori-Tanaka tensor is also calculated, which give the consistent values of strain into each phase. These strains are compared to initial ones, and corrected by a Newton Raphson algorithm.

\section{Finite Element Model}

The imposed cycle is composed by 5 steps: from an initial austenitic ring, a cooling is applied to form twinned martensite. Then, a pressure into internal diameter of the SMA ring increases its internal diameter. The elastic ring is placed into the SMA ring, and a heating induces the reverse transformation and the tightening. Finally, a cooling is applied until the room temperature.

The studied device is composed of axisymmetric geometry, loading and boundary conditions. Thus, axisymmetric model is considered. Quadrilateral axisymmetric elements are adopted to mesh the rings. A reduced integration technique is considered. For thin one, elements with a length of $0.22 \mathrm{~mm}$ are chosen in order to have 4 elements in the thickness. In thick one, elements with length of $0.60 \mathrm{~mm}$ are chosen, which induces 6 elements in thickness. It has been verified that the element length does not influence the results. Figure 6 represents the mesh for the two configurations.

A preliminary study was conducted to determine the initial
$\mathrm{Ni}_{47} \mathrm{Ti}_{44} \mathrm{Nb}_{9}$ rings size: they are opened by the supplier Intrinsic Devices before delivery. The internal diameter before this step is unknown. The opening of the ring is through the orientation of twinned martensite variants, and it generates gradients of properties in the ring. It is essential to model this stage of the tightening cycle to accurately describe the real case. For both rings, simulations are performed with opening several internal diameter values, until the value after opening is identical to that of the ring provided.

Thick rings case The ring diameter in opened state is $25.94 \mathrm{~mm}$. The transformation strain is assumed to reach its saturation value $(2 \%)$ at the opening of the ring. Several simulations have been conducted, and the determined initial internal diameter of the ring is $25.30 \mathrm{~mm}$.

Thin rings case The ring diameter in opened state is $25.90 \mathrm{~mm}$, and the determined initial internal diameter of the ring is $25.34 \mathrm{~mm}$.

The stress field evolution during cycle into SMA rings is represented in Fig. 7.

\section{DISCUSSION}

Figure 8 shows the comparison between experimental and numerical results for thin (A) and thick (B) devices. In both cases, the temperature at which the contact occurs between SMA and Inconel rings is well predicted, at $60{ }^{\circ} \mathrm{C}$. Once contact is made, the tightening pressure evolution with temperature in experimental study is $0.27 \mathrm{MPa} /{ }^{\circ} \mathrm{C}$ and $1.6 \mathrm{MPa} /{ }^{\circ} \mathrm{C}$ for thin and thick configurations, respectively. The modeled value is about $0.25 \mathrm{MPa} /{ }^{\circ} \mathrm{C}$ in thin case, and $1.6 \mathrm{MPa} /{ }^{\circ} \mathrm{C}$ in thick one which are very close to the experimental ones.

The main difference between experimental and numerical analysis is the saturation, which numerically appears early in both cases and underestimates the contact pressure generated. In thin configuration, the predicted pressure at the end of heating is 19 $\mathrm{MPa}$ while experimental results give $20 \mathrm{MPa}$. Similarly, predicted and experimental results are 75 and $80 \mathrm{MPa}$ in thick configuration. However, the contact pressure difference never exceeds $7 \%$.

On cooling, the large temperature hysteresis of $\mathrm{Ni}_{47} \mathrm{Ti}_{44} \mathrm{Nb}_{9}$ induces that the shape memory ring stay totally austenitic from 175

${ }^{\circ} \mathrm{C}$ to $-30{ }^{\circ} \mathrm{C}$. The behavior of this ring is only governed by thermoelasticity of austenite. Thus, the device can be considered as two thermoelastic rings in contact, with different thermal expansion coefficients. Indeed, $\mathrm{Ni}_{47} \mathrm{Ti}_{44} \mathrm{Nb}_{9}$ and Inconel 718 thermal expansion coefficients are respectively 8 and $13 \mu \mathrm{m} /\left(\mathrm{m}^{\circ} \mathrm{C}\right)$. A temperature increase induces a greater expansion of the Inconel 718 inner ring and increases the tightening pressure. Similarly, a temperature decrease induces a decrease of tightening pressure. 


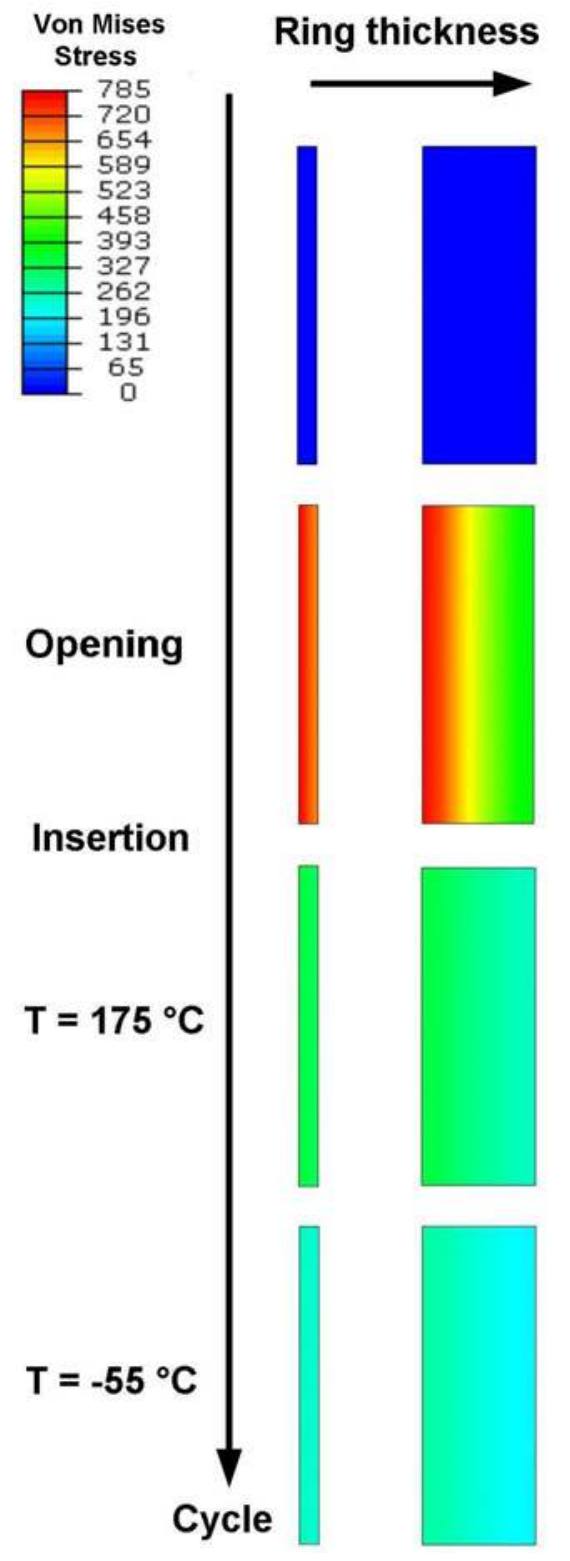

FIGURE 7. STRESS FIELD INTO SMA RINGS AT DIFFERENT STEPS FOR THIN (LEFT) AND THICK (RIGHT) CONFIGURATIONS

The behavior of the device is only governed by the expansion difference between the two rings. In thin ring configuration, the simulated tightening pressure evolution is identical to the experimental one, as $0.015 \mathrm{MPa} /{ }^{\circ} \mathrm{C}$. However, in thick one, experimental evolution is $0.12 \mathrm{MPa} /{ }^{\circ} \mathrm{C}$ while predicted one is about $0.05 \mathrm{MPa} /{ }^{\circ} \mathrm{C}$. This important difference can be attributed to analytic equation to calculate the contact pressure (Eqn. 1) which does not take into account the thermal effect. Another explana-
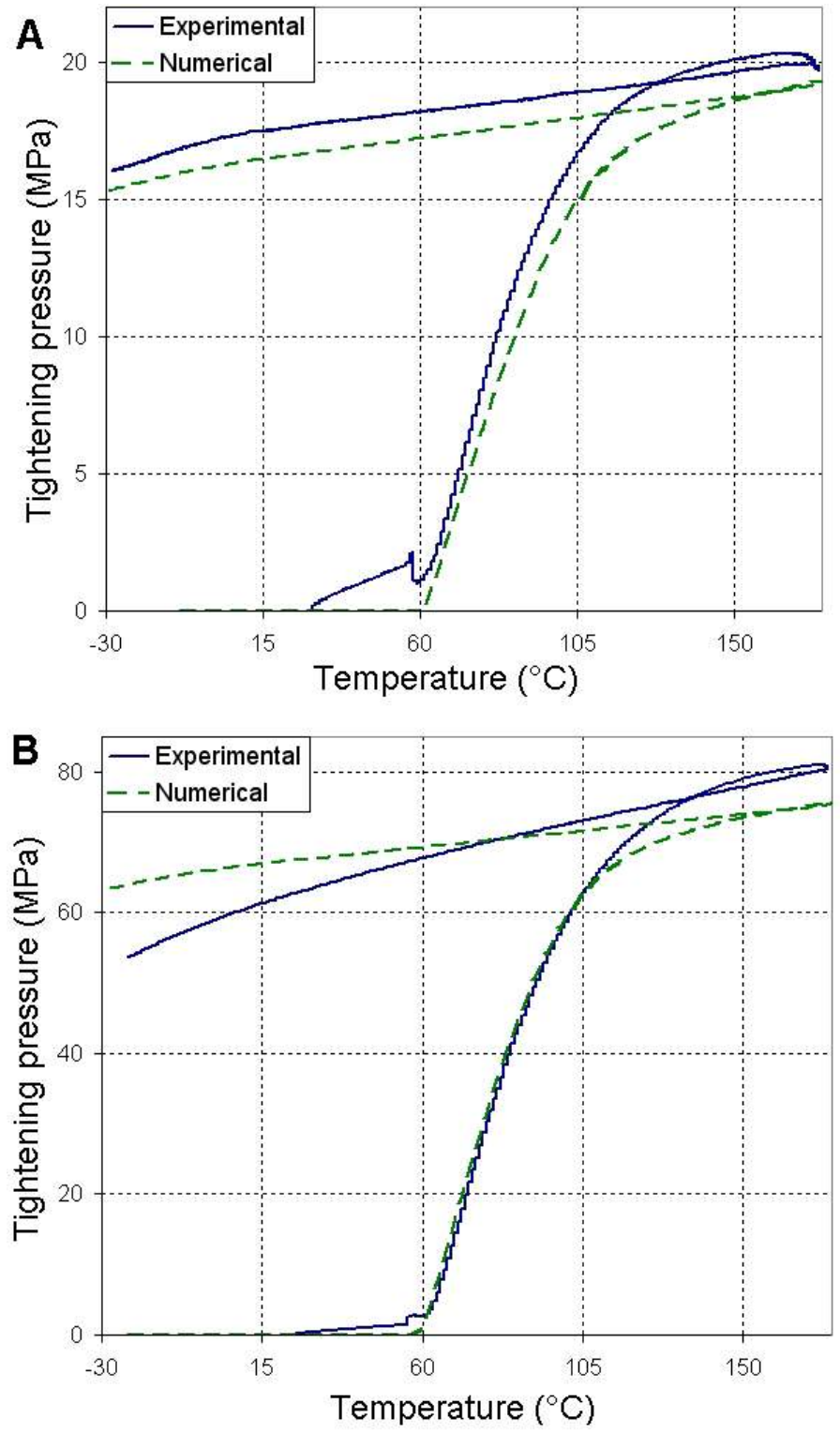

FIGURE 8. COMPARISON BETWEEN EXPERIMENTAL AND NUMERICAL RESULTS FOR THE THIN (A) AND THICK (B) RING DEVICES

tion may be the experimental error acquisition performed using a thermocouple placed on the surface of the inner ring, where the temperature is not exactly the same as in the $\mathrm{Ni}_{47} \mathrm{Ti}_{44} \mathrm{Nb}_{9}$ ring. In both cases, tightening pressure difference between experimental and numerical analysis is lower than $10 \%$. Other comparisons experiment/model were performed for various $t_{R} / L_{R}$ ratio. The validity of the model is not established for the ratio greater than 2.5 where there is a significant stress gradient in the ring during opening. 


\section{CONCLUSION}

$\mathrm{Ni}_{47} \mathrm{Ti}_{44} \mathrm{Nb}_{9}$ proposed model is used to simulate the shape memory behavior of tightening rings. Comparisons with experience show that model and adopted material parameters give an accurate simulation of rings tightening. This model can be used for industrial applications design. However, simulations with rings thickness 2.5 times greater than length are not possible. Indeed, the opening of the ring induces a matrix plastic strain, not taken into account in the model. Further investigations will be conducted in order to take into account the effect of a plasticity gradient in NiTi matrix through the thickness, and material parameter evolution (maximum transformation strain, transformation temperature evolution with stress) with plastic strain.

\section{ACKNOWLEDGMENT}

This research has been performed within a project funded by Schlumberger SRPC (Clamart). The authors are grateful to Schlumberger for its financial support, and to Frederic Pauchet and Jean-Luc Garcia.

\section{REFERENCES}

[1] Melton, K. N., Proft, J. L., and Duerig, T. W., 1989. "Wide Hysteresis Shape Memory Alloys Based on the NiTiNb System.”. The Martensitic Transformation in Science and Technology., pp. 191-198.

[2] Zhao, L. C., Duerig, T. W., Justi, S., Melton, K., and Proft, J. L. Y., 1990. "The study niobium rich precipitates $\mathrm{Ni}$ Ti Nb shape memory alloy.”. Scripta metallurgica, 24, pp. 221-225.

[3] Piao, M., Otsuka, K., Miyazaki, S., and Horikawa, H., 1993. "Mechanism of the as temperature increase by predeformation in thermoelastic alloys.". Materials Transactions, JIM, 34, pp. 919-929.

[4] He, X. M., and Rong, L. J., 2004. "DSC analysis of reverse martensitic transformation in deformed Ti-Ni-Nb shape memory alloy.”. Scripta Materialia, 51, pp. 7-11.

[5] Zhang, C. S., Wang, Y. Q., Chai, W., and Zhao, L. C., 1991. "The study of constitutional phases in a $\mathrm{Ni}_{47} \mathrm{Ti}_{44} \mathrm{Nb}_{9}$ shape memory alloy.". Materials Chemistry and Physics, 28, pp. 43-50.

[6] Piotrowski, B., 2010. “Analyse numérique et expérimentale du comportement d'un alliage à mémoire de forme avec précipités $\left(\mathrm{Ni}_{47} \mathrm{Ti}_{44} \mathrm{Nb}_{9}\right)$ : application à la connectique". Phd thesis, Nancy University.

[7] Piotrowski, B., Ben-Zineb, T., Patoor, E., and Eberhardt, E., 2010. "Numerical and experimental analysis of niobium precipitates effect on the $\mathrm{Ni}_{47} \mathrm{Ti}_{44} \mathrm{Nb}_{9}$ Shape Memory Alloy behavior.". Submitted to International Journal of Plasticity.
[8] Chemisky, Y., Duval, A., Tahiri, V., Eberhardt, A., and Patoor, E., 2008. Modeling the behavior of an SMAElastomer composite. proceedings of ICOMAT, Santa Fe, USA.

[9] Wilkins, M. L., 1964. Calculation of Elastic-Plastic Flow. Methods of Computational Physics.

[10] Simo, J. C., and Hughes, T. J. R., 2000. Computational Inelasticity. Springer.

[11] Mori, T., and Tanaka, K., 1973. "Average stress in matrix and average elastic energy of materials with misfitting inclusions.”. Acta Metallurgica, 21, pp. 571-574.

[12] Chemisky, Y., Duval, A., Piotrowski, B., Ben Zineb, T., Tahiri, V., and Patoor, E., 2009. "Numerical tool for SMA materials simulation - Application to composite structures design.". Smart Materials and Structures, 1, pp. 1-2.

[13] He, X. M., Zhao, L. Z., Zhang, S. F., Duo, S. W., and Zhang, R. F., 2006. "Study of the thermal physical properties of $T i_{44} N i_{47} N b_{9}$ wide hysteresis shape memory alloys.". Materials Science and Engineering A, 441, pp. 167-169.

[14] Xiao, F., Ma, G., Zhao, X., Xu, H., Jiang, H., and Rong, L., 2008. A novel TiNiNb shape memory alloy with high yield strength and high damping capacity. International Conference on Smart Materials and Nanotechnology in Engineering.

[15] Liu, Y., Mahmud, A., Kursawe, F., and Nam, T. H., 2006. "Effect of pseudoelastic cycling on the Clausius-Clapeyron relation for stress-induced martensitic transformation in NiTi.”. Journal of Alloys and Compounds, 449, pp. 8287.

[16] Wang, X., Xu, B., and Yeu, Z., 2008. "Phase transformation behavior of pseudoelastic NiTi shape memory alloys under large strain.”. Journal of Alloys and Compounds, 463, pp. 417-422. 